\title{
El fado y su vinculación con el territorio como elemento identitario de la sociedad portuguesa
}

\author{
The Fado and its Association with the Terrotory as an Identity Element of \\ the Portuguese Society
}

\author{
Gustau Olcina Sempere \\ Universitat Jaume I \\ golcina@edu.uji.es
}

ORCID iD: https://orcid.org/0000-0001-8655-9945

\begin{abstract}
RESUMEN
El presente estudio tiene por objetivo poner de manifiesto los orígenes y la funcionalidad del fado en la sociedad portuguesa. Por tanto, estudiaremos los orígenes, la evolución y la vitalidad del fado como elemento de integración social, así como los aspectos más importantes para el reconocimiento y valoración del fado, destacando principalmente el reconocimiento como Patrimonio Inmaterial de la Humanidad por la Unesco en el año 2011. Por otro lado, el estudio también describe cuáles son los sentimientos que transmite el fado, centrándonos concretamente en aquellas áreas del cerebro que se activan cuando escuchamos el fado, debido a que los avances que nos ofrecen las investigaciones en neurociencia nos proporcionan una información muy veraz para conocer qué áreas del cerebro están implicadas en la audición de la música. Finalmente, también pretendemos analizar qué aspectos intrínsecos tiene el fado como herramienta de identidad, además de conocer la vinculación del fado con el territorio, principalmente en la sociedad portuguesa. Asimismo, conoceremos la influencia del fado como símbolo de identidad de los portugueses y de la riqueza que ha supuesto la interacción del fado con otras culturas.
\end{abstract}

Palabras clave: Fado, funcionalidad, identidad, sentimientos, vinculación al territorio.

\section{AbStraCt}

The present research aims at showing the origins and the functionality of the Fado in the portuguese society. Therefore, we will study the origins, the evolution and the vitality of the Fado as element of social integration, as well as the most important aspects for the recognition and assessment of the Fado, highlighting mainly the recognition as Intangible Heritage of Humanity by Unesco in the year 2011. On the other hand, the analysis also describes what feelings the Fado transmits, focusing specifically on that brain areas that are activated when the Fado is listened to, 


\section{GuSTAU OLCINA SEMPERE}

are transmitted by the Fado, and specifically we will discover which areas of the brain are given that the advances provided by neuroscience research offer us very truthful information in order to find out what brain areas are involved in listening to music. Finally, we are also interested in examining what intrinsic aspects the Fado has as tool of identity, in addition to knowing the link between the Fado and the territory, mainly in the portuguese society. Likewise, we will know the influence of the Fado as the symbol of identity of the Portugueses, and of the wealth that the interaction between the Fado and other cultures has implied.

Key words: Fado, Functionality, Identity, Feelings, Territorial Link.

Olcina Sempere, G. (2018). El fado y su vinculación con el territorio como elemento identitario de la sociedad portuguesa. Cuadernos de Investigación Musical, 5, 161-177.

\section{INTRODUCCIÓN}

Los orígenes del género musical portugués conocido con el nombre de fado surgen el Lisboa en la década de 1840. El fado se visibiliza asociado con la imagen de María Severa, cantaora y guitarrista de Mouraria. La relación amorosa de María Severa con don Francisco de Paula Portugal y Castro, conde de Vimioso, acentúa aún más el prestigio de María Severa. Esta relación amorosa entre las citadas figuras hace posible que el fado pueda escucharse en el palacio de Vimioso e introducir el fado en la nobleza portuguesa, propiciando con ello un proceso de consolidación del fado en la sociedad portuguesa durante la segunda mitad del siglo XIX (Nery, 2004; Brito, 1999).

El proceso de difusión del fado en el ámbito internacional empieza hacia los años 30, transportando el fado hacia Brasil y África. Dicho proceso de internacionalización del fado se pone claramente de manifiesto a mediados del siglo XX mediante la figura de Amália Rodrigues, la cual ha sido considerada como una de las principales fadistas de todos los tiempos. Mediante la figura de Rodrigues es cuando el fado se considera un icono de la cultura portuguesa en el ámbito mundial (Pereira, 2008). Aproximadamente, en 1976 es el momento en que se produce una mayor eclosión del fado, ya que es en este año cuando se elabora el álbum Um Homem na Cidade de Carlos do Carmo, uno de los principales referentes de la música en Lisboa. Ya en los años 90 es cuando el fado abarca el ámbito más internacional con Cristina Branco, Misia y Mariza.

Debido a la funcionalidad del fado en la sociedad portuguesa, el fado adquiere una fuerte vinculación con la clase obrera y, por tanto, tiene su desarrollo en las regiones cercanas a las zonas portuarias. Las diferencias laborales entre clases sociales fomentan la consolidación de partidos políticos sobre todo con ideología de izquierdas que utilizan el fado como si fuese un himno, dando pie con ello al nacimiento de los fados operarios o fados socialistas. Además, en estos fados se reivindican los derechos de los trabajadores, realizando también una crítica a la iglesia (Sergl, 2007).

El fado es considerado un elemento constitutivo de la sociedad portuguesa y patrimonio inmaterial de la humanidad por la UNESCO desde 2011. En cuanto a la 


\section{EL FADO Y SU VINCULACIÓN CON EL TERRITORIO COMO ELEMENTO IDENTITARIO DE LA SOCIEDAD PORTUGUESA}

principal característica que lo constituye, destaca que es cantado por una persona y acompañado por la guitarra, entre las cuales destaca la guitarra portuguesa ${ }^{1}$ y la española ${ }^{2}$, aunque desde hace algunos años el acompañamiento instrumental del fado se ha enriquecido y en la actualidad suele ser acompañado por una guitarra, dos guitarras portuguesas y una guitarra bajo (Lopes, 2011). Uno de los guitarristas más destacados en los inicios del fado fue Armando Augusto Freire, el cual realizó un gran número de fados. Posteriormente son reconocidos como guitarristas de fado Raúl Carvalhinho, Jaime Santos, Nery, y José Fuentes Rocha (Pereira, 2008). El fado se canta tanto en grandes conciertos, los cuales albergan a multitud de personas, como también en las conocidas casas de fado, las cuales disponen de un espacio mucho más reducido pero más íntimo. Además, también es cantado por aficionados en diversas asociaciones que forman parte del entorno histórico en la ciudad de Lisboa (Lopes, 2011).

Los temas que representa el fado son muy variados, desde la nostalgia, los celos, el amor, la tragedia y el deseo hasta las dificultades de la vida cotidiana en el día a día de la sociedad portuguesa. Generalmente, se canta con un carácter melancólico, ya que se canta al amor perdido, al destino, a las miserias de la vida, así como también a la crítica social. Por lo tanto, cada fado canta una historia y una realidad social. Además, tiene la magia de trasladar al oyente a lugares melancólicos y nostálgicos, con la finalidad de poder descubrir o redescubrir una situación. El fado tiene la virtud de combinar a la perfección la música con la poesía, extendiéndose su práctica en Lisboa y Coimbra ${ }^{3}$ (Lopes, 2011).

\footnotetext{
${ }^{1}$ La guitarra portuguesa es un cordófono pulsado en forma de pera, con seis pares de cuerdas dobles, donde las tres primeras parejas (empezando por la más fina y aguda) comparten afinación con las tres siguientes parejas, que están afinadas con una octava de diferencia (Ribeiro y Inácio, 2016).

${ }^{2}$ La guitarra española es un instrumento de seis cuerdas con una caja en forma de ocho, compuesta por el clavijero, el mástil con trastes fijos, con fondo plano, aros laterales y boca en la mitad superior de la tapa armónica (Andrés,1995).

${ }^{3}$ Las diferencias entre el fado de Coimbra y el de Lisboa a propiciado la existencia de dos tipos de guitarras para acompañar el fado, la guitarra de Coimbra y la de Lisboa, pudiéndose encontrar todavía determinadas guitarras con particulares diferencias conociéndose como guitarras de Porto (Figura 1). Una de las características más distintivas entre las guitarras portuguesas es que el cuerpo tiene forma de pera, teniendo la cabeza del modelo de Coimbra forma de lágrima, y el modelo de Lisboa forma de espiral (Inácio, Santiago y Cabral, 2004).
} 


\section{GuSTAU OLCINA SEMPERE}

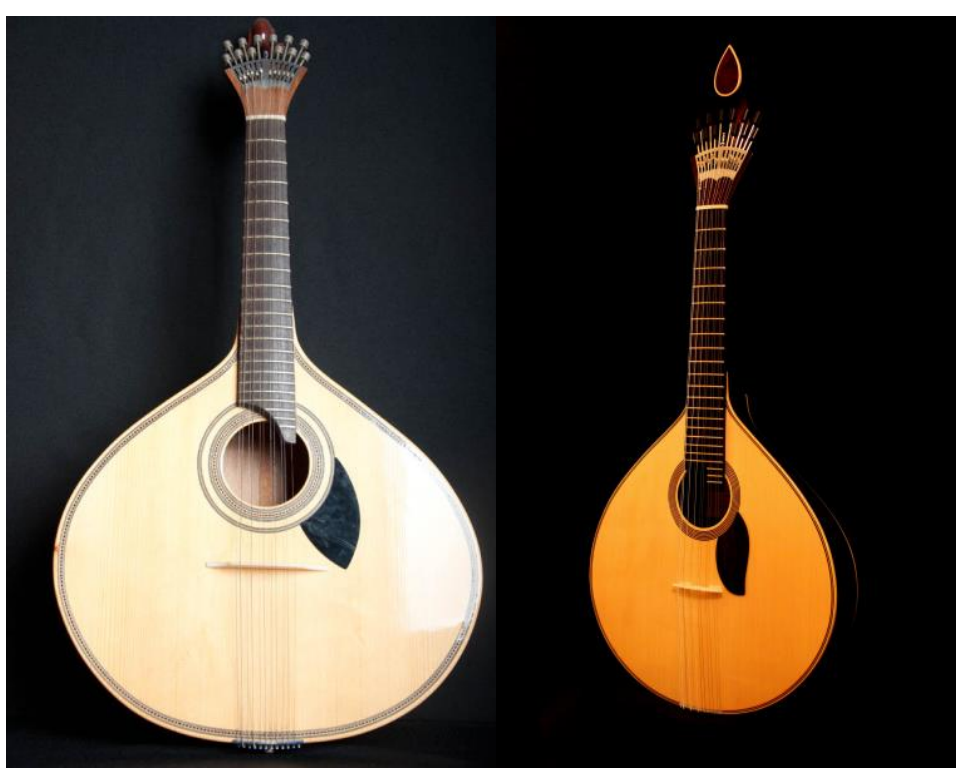

$\mathrm{b}$

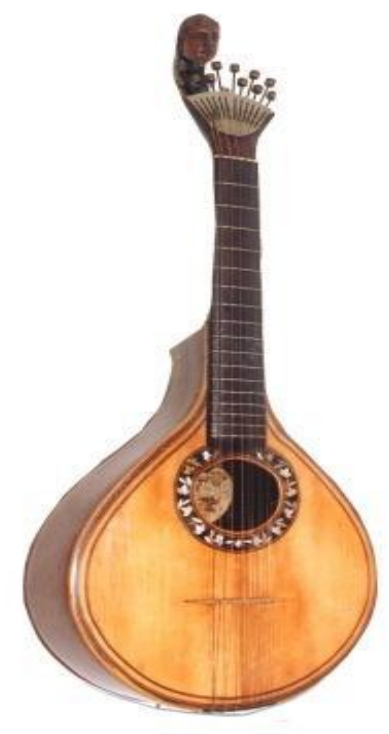

C

Fig. 1: Guitarras portuguesas:

a) Lisboa, b) Coimbra, c) Porto

Las primeras letras que se utilizan en los fados tienen un carácter anónimo, ya que, como sucede en la mayoría de la música vocal de nuestros antepasados, las canciones eran transmitidas de manera oral sin la necesidad de tener la letra escrita. Concretamente, en el caso del fado, es aproximadamente en los años 20 cuando surge todo un abanico de poetas populares, como Gabriel de Oliveira, Carlos Conde y Frederico de Brito. Posteriormente, a mediados del siglo XX es la voz de Amália Rodrigues la transmisora del fado con la utilización de la poesía clásica (Pereira, 2008).

Los flujos migratorios que se producen en Portugal, tanto de origen brasileño como africano, generan nuevos procesos de transculturación que influyen en el fado, como es el caso de la incorporación de piezas danzadas e instrumentales que traían los esclavos procedentes de otros territorios como la modinha y el lundu. Por lo tanto, podríamos considerar que el fado ha sido influenciado por las diversas aportaciones musicales y culturales con una notoria influencia de la música árabe, apreciándose en la tensión melódica, el uso del tono menor, el uso del vibrato muy particular de los fadistas, el reiterado uso de la tónica en los fados más tristes, y las ornamentaciones vocales (Castelo-Branco, 2000; Romero, 2003, Carou, 2013). Por lo tanto, en el fado se percibe una extraordinaria riqueza visual gracias al conocimiento y difusión del fado danzado, donde se puede apreciar con claridad la notable influencia de las danzas y bailes árabes.

Desde el punto de vista de las emociones, la música transmite diferentes estados de ánimo o placer en las diferentes culturas o sociedades, aunque no se conozca la lengua portuguesa. Según los estudios de neurociencia que se han realizado para conocer la influencia de la música en el cerebro, ponen de manifiesto que mientras escuchamos música nuestro cerebro obtiene placer y, por lo tanto, contribuye al desarrollo integral del individuo (Salimpoor y cols, 2013). Así, el fado contribuye a generar diferentes estados anímicos. 


\section{EL FADO Y SU VINCULACIÓN CON EL TERRITORIO COMO ELEMENTO IDENTITARIO DE LA SOCIEDAD PORTUGUESA}

Debido al carácter integrador que tiene el fado, éste se considera como el alma del pueblo portugués. Este carácter le otorga al fado un sentido de identidad y pertenencia en la sociedad portuguesa (Gomes, 2010). Además, esta forma de entender el fado como un elemento social e identificativo de la sociedad portuguesa nos hace reflexionar y analizar la relación entre las actuaciones diarias de los conciertos de fado y su funcionalidad como una necesidad sociocultural en la vida diaria de los portugueses (Mazzarino y cols, 2011).

Según Mortaigne (2003) el fado puede considerarse como el canto de un país, así como un estado emocional que viaja entre la tristeza y la alegría. Por todo esto, el fado puede considerarse como algo más que una sucesión de sonidos que deleitan nuestros oídos. Además, el fado se convierte en un vehículo de comunicación no solo entre la sociedad portuguesa, sino también con cualquier otra nacionalidad, no siendo la lengua portuguesa un impedimento para conocer los sentimientos y mensajes que lleva implícito el fado (Arraut y Vielliard, 2004).

También, el fado concebido como una manifestación artística es capaz de transmitir los sentimientos y emociones de manera sencilla y transparente (Fazio, 2016). Estas emociones o sentimientos que transmiten las diferentes manifestaciones artísticas son fruto de una construcción social y en constante cambio, de modo que contribuyen a conocer los aspectos socioculturales indagando en la subjetividad e interiorización del ser humano (Bolaños, 2016).

Llegados a este punto, a continuación conoceremos la relación de las emociones y la música del fado en el ser humano y, posteriormente, conoceremos la vitalidad del fado como elemento identificativo de la sociedad portuguesa para concluir con unas consideraciones finales.

\section{LAS EMOCIONES Y LA MÚSICA: LOS SENTIMIENTOS DEL FADO}

De entre los estudios que se han realizado para conocer el procesamiento de la música, destaca el estudio realizado por Levitin y cols (2004) con pacientes con autismo donde se pudo apreciar que la música se procesa de manera modular. Esta evidencia también se ha podido observar en pacientes con el síndrome de Asperger (un tipo especial de autismo), produciéndose en las personas con autismo un deterioro de determinadas capacidades musicales (Levitin, 2000).

Según Levitin (2008), el aspecto rítmico de la música aprovecha más el cerebro que el lenguaje, implicando a estructuras cerebrales que participan en las emociones, la motivación y la recompensa, viéndose implicado principalmente el hemisferio izquierdo para el lenguaje, y ambos hemisferios cerebrales para la música. Para conocer qué sensaciones nos produce la música en el cerebro, se han realizado diversas investigaciones utilizando para ello la técnica de la resonancia magnética (RM). Un estudio realizado por Salimpoor y cols. (2013), donde se pone de manifiesto qué áreas cerebrales están implicadas en los procesos de recompensa que genera la escucha de la música en nuestro cerebro, defiende que 


\section{GuSTAU OLCINA SEMPERE}

principalmente el núcleo accumbens es la zona que se activa cuando escuchamos música. Además, otras áreas del cerebro, como la corteza auditiva, la amígdala y las regiones prefrontal y ventromedial, también mostraron un aumento de actividad al escuchar música.

Desde una concepción anatómica del cerebro, la obtención del placer que sentimos cuando escuchamos música, se debe a que, nuestro cerebro cuando escucha música genera una sustancia denominada dopamina, indicándonos que se está obteniendo placer, al igual que sucede con la comida, el sexo o las drogas (Salimpoor y cols. 2013).

Además, otro estudio realizado por Blood y cols. (1999) mediante la técnica de tomografía por emisión de positrones (TEP), realizada a participantes no músicos, demostró que si se escuchaban acordes consonantes se activaba el área orbitofrontal y la región subcallosa del hemisferio derecho asociándolos a sensaciones positivas, mientras que si escuchaban acordes disonantes se activaba el giro parahipocampico ipsilateral asociándolo con sensaciones desagradables.

En cuanto al fado, su lenguaje transmite multitud de emociones gracias a su capacidad de expresión (Valverde, 1999). Además, no solo se perciben los gestos, palabras, expresiones faciales de los intérpretes del fado, sino que también, dichas expresiones que son vistas y oídas por los oyentes, también son vividas y sentidas por los cantantes del fado.

Por otro lado, cabe también destacar que en la interpretación del fado los cantantes lo transmiten con la intención de comunicar a los oyentes los sentimientos que quiere visibilizar el fado (Delgado, 2012). Woody y McPherson (2010) manifiestan que los músicos son conscientes de la necesidad de saber cómo pueden conectar con la música que van a interpretar para que sea expresiva. Por lo tanto, deben relacionar todos los elementos del discurso musical, como el timbre, la melodía, el ritmo y la armonía, con la finalidad de conseguir una interpretación expresiva.

Asimismo, la gestión de las emociones del músico en su vida diaria y su preparación emocional para la interpretación son elementos decisivos para una adecuada interpretación expresiva. Así, la forma en que los cantantes interpreten y dramaticen con su cuerpo el fado determinará en gran medida que los espectadores acentúen los sentimientos y emociones que genera el fado (Valverde, 1999; Woody y McPherson, 2010).

En definitiva, el fado puede transmitir diversas emociones principalmente por su sonido, ya que no solo conmueve a los portugueses, sino que puede despertar la sensibilidad también de los extranjeros, que no teniendo ningún conocimiento de la lengua portuguesa llega a estremecer a sus corazones. Este aspecto intrínseco del fado como motivador de los sentimientos exige una adecuada estructura sonora y melódica, así como una oportuna gesticulación y dramatización de los cantantes en su interpretación (Valverde, 1999).

Además, una de las características que se le ha otorgado al fado es su carácter emotivo y melancólico, debido a la utilización del lenguaje con un alto contenido melodramático, con la intención de hacer viajar a los oyentes a situaciones trágicas como la 


\section{EL FADO Y SU VINCULACIÓN CON EL TERRITORIO COMO ELEMENTO IDENTITARIO DE LA SOCIEDAD PORTUGUESA}

miseria, la tristeza y el destino (Valverde, 1999). A este respecto, Castañón (2002) manifiesta que la gran fadista Amália Rodrigues ${ }^{44}$ decía que lo más importante del fado era poder percibir sus sentimientos, afirmando que el fado carece de una explicación y comprensión y, por lo tanto, para conocer realmente lo que quiere decir el fado es fundamental sentirlo. Además, también nos decía Amália Rodrigues que la esencia y significación del fado es conformarnos con lo que tenemos, es un canto a aquello que es imposible modificar, es una lucha constante por cuestionarnos cosas aunque sepamos que no hay ninguna respuesta posible.

Asimismo, el fado refleja de una manera veraz y transparente los sentimientos de Portugal, donde siempre se esperaba que el mar ofreciera deseos y esperanzas, ya que los marineros no sabían si iban a regresar y sus familias no tenían la certeza de que siempre regresaran. Este contexto generaba melancolía, añoranza y soledad, donde el llanto y la esperanza eran una costumbre (Fischerman, 2005).

En definitiva, el fado se concibe como una excelente herramienta para transferir los sentimientos, debido a que los cantantes interactúan con el público y contribuyen a que los propios estados emocionales que viven y transmiten los cantantes de fado, se conviertan en sentimientos reales y propios de los oyentes del fado (Luiz, 2005). Asimismo, las diferentes inflexiones, cambios y matices que desarrollan los fadistas hacen que los oyentes entiendan mejor el mensaje que lleva intrínseco el fado y que conecten con los sentimientos que transmite el fado, convirtiéndose la voz de los intérpretes en un elemento que genera efectos terapéuticos y satisfactorios para el corazón y espíritu de los oyentes de este género (Mendes y Próchno, 2006). El fado ha sido considerado tradicionalmente como una música triste, incluyéndose en muchos fados las temáticas nostálgicas y fatalistas (Halpern, 2004) como en el fado "O Fado Chora-se Bem":

\footnotetext{
Mora numa rua escura

A tristeza e amargura,

Angústia e a solidão.

No mesmo quarto fechado

Também lá mora o meu fado

E mora o meu coração

E mora o meu coração $(\ldots)^{55}$.
}

\footnotetext{
${ }^{4}$ Amália Rodrigues influyó en la reformulación del fado en todos los aspectos, con el uso del vestido y chal negros, el posicionamiento del fadista delante de los guitarristas, su lenguaje gestual, y su peculiar timbre de voz descrita poéticamente como la voz de plata (Nery, 2004, 2005, 2010).

5 “O Fado Chora-se Bem” (Amália Rodrigues / Fontes Rocha).
} 


\section{Gustau OlCiNA SEMPERE}

\section{ESTRUCTURA ESTÉTICA Y MUSICAL DEL FADO}

En cuanto a la estructura y composición de los primeros fados, no existen muchas diferencias entre los fados cantados y los que son bailados. La organización armónica del fado está formada por una combinación de acordes entre los grados tonales de tónica y dominante, siendo difícil el uso del acorde de subdominante como preparación para la cadencia final. Por otro lado, en los fados se combina tanto el modo mayor como el menor, aunque predomina principalmente el menor, ya que le confiere un carácter más melancólico y nostálgico (Sergl, 2007). Véase al respecto el "Fado das lagrimas".

\section{Fado das lagrimas}

Transcrição de Octávio Sérgio
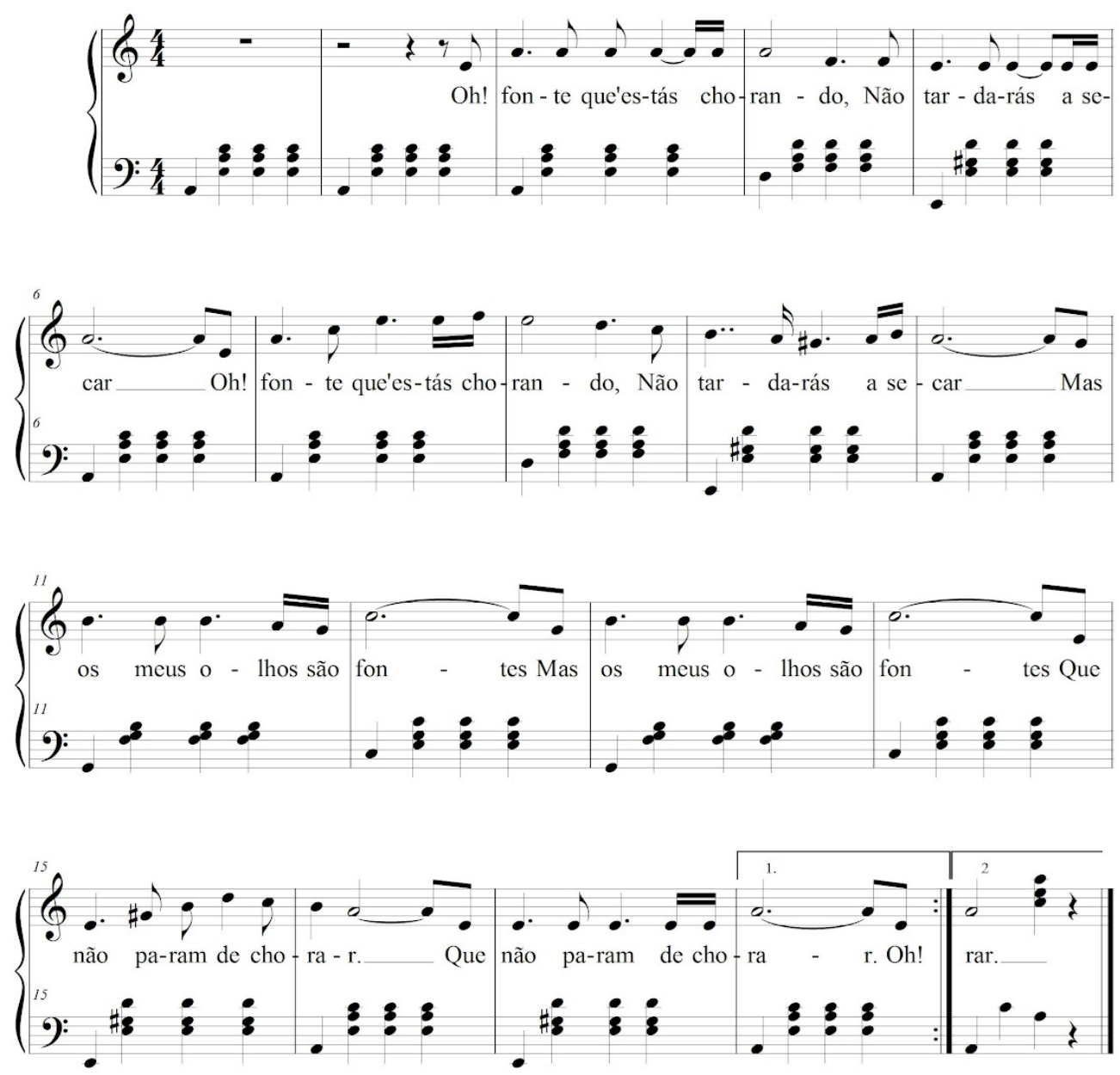

Fig. 2: "Fado das lagrimas". 


\section{EL FADO Y SU VINCULACIÓN CON EL TERRITORIO COMO ELEMENTO IDENTITARIO DE LA SOCIEDAD PORTUGUESA}

En lo referente al ritmo, predominan los ritmos sincopados y un tempo no muy rápido, ofreciendo la posibilidad tanto a los instrumentistas como a los cantantes de poder realizar improvisaciones. En cuanto a la estructura de las frases musicales, destaca la estructura de ocho compases, permitiendo de esta forma combinar y percibir con claridad la estructura armónica clásica de la combinación del acorde de tónica con la dominante. De entre cada una de las frases de ocho compases, los cuatro compases primeros sirven para presentar la melodía y los cuatro restantes para concluirla (Nery, 2005).

Otro aspecto relevante en el fado es el acompañamiento instrumental. Para ello utilizan la viola y la guitarra con la intención de sostener y apoyar al canto. Esta funcionalidad de la guitarra le confiere una importancia y prestigio gracias al uso de esta para acompañar el fado. También, al fado es acompañado por otros instrumentos en los salones más elitistas utilizando para ello la viola o el piano (Sergl, 2007).

Debido a la aceptación del fado como símbolo del nacionalismo portugués de las clases medias, el fado adquiere nuevos aires y se convierte en la canción que expresa los sentimientos más íntimos del estilo romántico. Esta consideración del fado en estos estamentos sociales favorece la incorporación de nuevos instrumentos para acompañarlo como el piano. Además, la difusión comercial del fado en las postrimerías del siglo XIX hace posible que pueda llegar con facilidad a la clase burguesa (Nery, 2005).

Por otro lado, es también importante destacar el significativo reconocimiento del fado por parte de los estudiantes universitarios, y sobre todo los pertenecientes a la universidad de Coímbra. Es en este contexto universitario cuando el fado adquiere una nueva forma y estructura utilizando las formas poéticas con un alto nivel de erudición, dando lugar al fado de repetición ${ }^{6}$ o al fado esdrújulo ${ }^{7}$ (Nery, 2005).

También, la voz es considerada como uno de los aspectos más notorios para conocer estéticamente el fado. Para la interpretación del fado es necesario un elevado dominio de la voz, tanto desde el punto de vista tímbrico como articulatorio. Además, es igualmente necesario que los cantantes del fado posean una amplia extensión vocal. Precisamente, estas características personales de cada cantante es uno de los aspectos que marcan la diferencia entre el fado lírico que se canta en Coimbra, en comparación con el fado lisboeta caracterizado por una voz más aterciopelada (Sergl, 2007).

Asimismo, una de las características más destacadas en la interpretación del fado es la improvisación mediante adornos y florituras, tanto de la vOz como de los instrumentos. Dicho aspecto le ofrece al fado un interés inesperado en el público, debido a que un mismo fado puede ser interpretado de manera diferente dependiendo de quién lo cante. El hecho de poder incluir el recurso de la improvisación ha sido posible gracias a su transmisión oral,

\footnotetext{
${ }^{6}$ En el fado esdrújulo, cada verso termina con una palabra esdrújula, siendo utilizadas palabras solemnes, comunes en los discursos eruditos, tales como: dialécticos, sofísticos, cinegéticos, pitagóricos y elegíacos.

${ }^{7}$ El "fado de repetición" tiene una composición rebuscada, "con alusiones literarias con pretensiones eruditas, con una fuerte influencia popular en muchas de las imágenes adoptadas" (Nery, 2005: 119), como en el ejemplo: "... El punto, rey de las señales; Rey de las cañas, el regaliz".
} 


\section{GuSTAU OLCINA SEMPERE}

siendo la creatividad de cada cantante la que ha proporcionado un tipo de improvisación u otra, garantizando así su carácter nostálgico y melancólico. También es característico el hecho de pasar de una nota a otra deslizándose por las otras notas realizando un glisando, así como también pasar rápidamente de una nota a otra realizando trinos.

Por otro lado, cabe destacar que también existen fados lentos y rápidos. Durante la interpretación del fado, el cantante es acompañado por las guitarras que se encargan en sostener el ritmo, propiciando una estabilidad rítmica que transmite al cantante una gran seguridad en la interpretación. Además, las guitarras transmiten el contexto emocional adecuado para que los fadistas puedan concentrarse en la interpretación del fado y crear un contexto adecuado al carácter y sentimientos que cada fado quiere transmitir.

\section{EL FADO Y SU VINCULACIÓN CON EL TERRITORIO}

Los estudios que se han realizado para conocer los efectos que produce la música en la sociedad ponen de manifiesto que es una excelente herramienta para favorecer la cohesión social, favoreciendo dicho aspecto la posibilidad de generar un determinado fondo bibliográfico y documental que sea capaz de transmitir y dar a conocer los valores, costumbres y señas de identidad de una determinada sociedad. Concretamente, en el caso del fado, Carvalho (1903) señala que, gracias la recopilación de un amplio repertorio de canciones, podemos conocer el fuerte carácter de identidad que transmite el fado, reflejando las costumbres y formas de vivir de la sociedad portuguesa.

A este respecto, según Ribeiro (1937), el fado es considerado como la manera de expresar los sentimientos de un pueblo. Además, también se concibe como una forma de vivir en el mundo actual, reflejando principalmente lo más íntimo de la sociedad portuguesa como un elemento social y emocional. De modo que el fado se convierte para los portugueses en un patrimonio cultural que une a la perfección la palabra y los sonidos. Esta conjunción entre la poesía y la música hacen que el fado se convierta en uno de los componentes más identificativos de la forma de ser de los portugueses, debido al carácter nostálgico que transmite la conjunción de las palabras y los sonidos, siendo inevitable la transmisión de un carácter melancólico y triste (Carvalho, 1903; Pimentel, 1904; Holton, 2006).

Según Smith (1997), la concepción del fado debe considerarse como un aspecto identificativo desde una concepción étnica, ya que considera el fado como uno de los elementos más distintivos de la cultura portuguesa. Dicha circunstancia tiene significado si entendemos el fado como una construcción poética que se convierte en la poesía popular de los portugueses.

A finales del siglo XVIII la burguesía incorpora en su día a día la práctica de bailes como el Lundu, el Fandango o la Modinha, para proporcionarles el entretenimiento en sus veladas, acompañados por unas melodías con carácter sentimental y nostálgico, con algunas secciones musicales destinadas también a la improvisación (Nery, 2005). Posteriormente, el debilitamiento de la burguesía y las diversas transformaciones sociales que atraviesa Portugal hacen que aproximadamente en 1830 los espacios que eran considerados como 


\section{EL FADO Y SU VINCULACIÓN CON EL TERRITORIO COMO ELEMENTO IDENTITARIO DE LA SOCIEDAD PORTUGUESA}

lugares de entretenimiento y prostitución se identifiquen como lugares donde se canta el fado, ya que son considerados como escenarios idóneos para cantarle a las tristezas y desencantos, considerándose esta época como originaria del fado lisboeta (Nery, 2005).

En otro orden, los diversos elementos que constituyen la identidad de cada persona están determinados y condicionados por unos conjuntos de acciones y procesos que desarrollamos en cada contexto social. En los procesos de socialización e interacción desarrollamos un conjunto de habilidades que ayudan a constituir la personalidad de cada sujeto y en consecuencia su identidad (Hinshelwood, 1992). Asimismo, Ramírez, (2017) afirma que la identidad se adquiere como fruto de las vivencias que se desarrollan en un determinado contexto sociocultural, estando determinada y condicionada por las vivencias y experiencias de cada persona.

Además, según Bodei, (2006) la asunción de la identidad requiere un intenso trabajo para vivir cada una de las experiencias vividas por cada individuo con la finalidad de no perder los recuerdos vividos durante toda su vida. De modo que la identidad abarca todo el ámbito de recuerdos de una persona, considerándose el olvido como un elemento negativo para la consolidación de la identidad (Souroujon, 2011).

A este respecto, el fado ha sido y es un elemento identificativo de la sociedad portuguesa, ya que ha sabido perdurar en el tiempo y constituirse como un ingrediente vital para el alma de los lisboetas. Los sentimientos que son comunicados a través del fado ayudan a formar el alma y la mente, constituyendo una determinada identidad, la cual establece un conjunto de valores centrados en la manera de expresarse, de sentir y de vivir, donde la consideración del destino se presenta como un elemento diferenciador e identitario del alma portuguesa (Lourenço, 1988).

Por otro lado, uno de los principales aspectos que constituyen al fado es el significado propio. Este aspecto se relaciona con el sentimiento de la melancolía, la añoranza y la nostalgia, considerándose dichos aspectos como esenciales y constitutivos de la identidad en la sociedad portuguesa. Estos sentimientos se remontan muchos siglos atrás, formando parte de las personas que realizaban trabajos en el mar, deduciendo con ello que el fado nace en mar y con los navegantes (Gomes, 2010).

Dichas consideraciones hacen que el fado sea considerado un género artístico reconocido por la UNESCO como Patrimonio Cultural Inmaterial de la Humanidad el día 27 de noviembre de 2011. Este reconocimiento contribuye a reafirmar el fado como un elemento de gran valor nacional y con fuertes vínculos identitarios con la sociedad portuguesa.

Asimismo, una de las principales características que constituyen el carácter fuertemente identitario del fado es el sentimiento que su música transmite. La interpretación del fado potencia determinados sentimientos como la esperanza, conformidad, el deseo, así como también el orgullo por la historia social y cultural de los portugueses (Halpern, 2004). 


\section{GuSTAU OLCINA SEMPERE}

La necesidad por crear y plasmar la historia del fado genera la creación de dos visiones diferentes sobre este género musical. La primera de ellas se plasma en dos obras literarias de Eça de Queiros, influenciada por las ideas de la Generación del 70, donde el fado no podría atender a las ideas propias de la moderna civilización europea. En cambio para Pinto de Carvalho (1903) y Alberto Pimentel (1904), este género musical figura como la expresión del alma nacional (Brito, 1999).

Por otro lado, el fado también tiene una gran repercusión en el cine. El fado ha sido fuente de inspiración de cineastas como Carlos Saura en su película documental Fados, estrenada en 2007, donde da a conocer la cultura portuguesa, la ciudad de Lisboa y, en general, un país tan cercano de España de lo que realmente pensamos (Sáez-González, 2007). Asimismo, la película Fados fue galardonada con el Premio Luso-español de Arte y Cultura, formando parte de su Trilogía junto con Flamenco, de 1995, y Tango, del año 1998.

Finalmente, el fado puede entenderse por su carácter socializador como una forma de expresión social, ya que comunica tanto las tristezas y miserias como también las alegrías y las virtudes de la sociedad portuguesa, siendo también una herramienta que facilita y contribuye a entender la vida de otra forma, así como percibir el mundo de manera diferente (Felisberto, 2013).

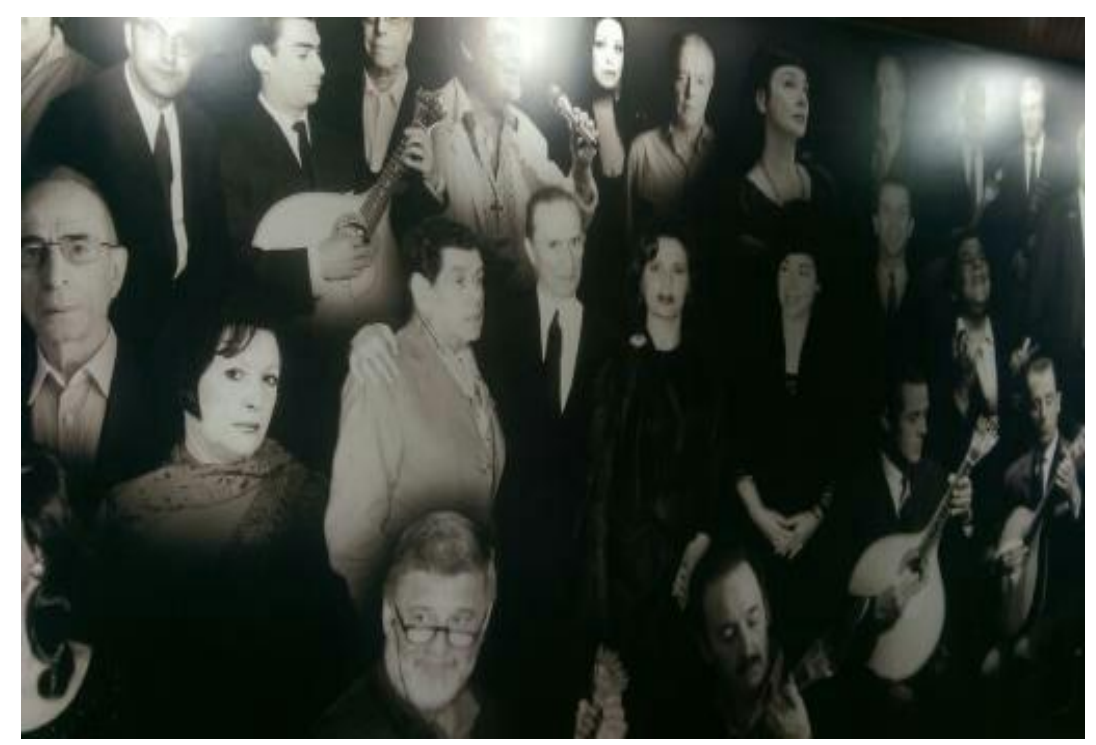

Fig. 3: Fadistas y guitarristas del fado.

\section{CONSIDERACIONES FINALES}

Las consideraciones realizadas sobre el fado le otorgan el valor como género artístico, el cual unifica a la perfección la poesía, la música, la pintura, la danza y la filosofía en muchos ámbitos de la sociedad portuguesa. También, el fado se ha convertido en un elemento de identidad que proporciona fuertes rasgos sociales y culturales, facilitando también el intercambio cultural con otras músicas y culturas. 


\section{EL FADO Y SU VINCULACIÓN CON EL TERRITORIO COMO ELEMENTO IDENTITARIO DE LA SOCIEDAD PORTUGUESA}

Asimismo, como hemos expuesto, el fado es reconocido como uno de los aspectos más influyentes y determinantes de la producción musical portuguesa. Mediante el fado se manifiesta y describe una manera de entender la vida. Principalmente, la conjunción entre poesía y música, característica en la composiciones del fado, pone su énfasis en los aspectos relacionados con el amor y de cómo afrontar las dificultades de la sociedad actual.

La funcionalidad del fado potencia en la sociedad portuguesa un carácter social y comunicador. Dicho carácter comunicador le otorga al fado una doble función. Por un lado, conecta con los aspectos sociales del día a día, y, por otro, enlaza con lo más íntimo de ser, debido a su carácter emotivo y sentimental estableciéndose una relación psicológica entre el fado y el oyente. De modo que el fado se concibe como un excelente instrumento que sabe acoplar a la perfección el binomio entre música y poesía, donde la importancia en conocer y comprender el significado de las palabras, acentuando aún más su carácter sentimental y melancólico.

La conceptualización del fado constituye un elemento de identidad del pueblo portugués, debido a que presenta los valores y las creencias de sus habitantes, fortaleciendo su práctica, desarrollando y difundiendo dichos aspectos socializadores e identitarios. De modo que, el fado abarca una perspectiva interdisciplinar debido a su vinculación y presencia en diversas disciplinas como la literatura, la poesía, la música, la pintura, la danza, la psicología y la filosofía.

Esta manifestación sociocultural transmitida a través del fado puede considerarse como un elemento reparador y reconstituyente del alma de las personas. La intención comunicativa que ofrece el fado garantiza que pueda suavizar las durezas del alma y en consecuencia suavizar los sentimientos de cada ser humano. De modo que el fado adquiere una vitalidad y fortaleza cuando se interpreta en directo, ya que conecta inmediatamente con los sentimientos que los oyentes tenemos escondidos y guardados, para actualizarlos y suavizarlos de manera placentera y satisfactoria.

Por lo tanto, podemos entender que el fado puede considerarse como un elemento integrador de la sociedad portuguesa, ya que los portugueses lo consideran una seña de identidad, aceptando con ello todo lo que el fado transmite como sus miserias, el deseo, la nostalgia, la tragedia, y las pequeñas historias de la vida. Todos estos ingredientes le otorgan al fado un carácter fuertemente descriptivo, donde cada fado transmite una realidad concreta que potencia la posibilidad de viajar en el tiempo y adquiere la peculiaridad de ser en esencia un elemento vital y conmovedor en todo momento.

Además, a proximidad del fado a los entornos poco elitistas como los arrabales portuarios y las tabernas le confieren al fado su carácter melancólico y nostálgico. En el significado más profundo del fado se define la saudade como un sentimiento contradictorio en cual la tristeza se convierte en alegría y la muerte en la vida. De modo que, mediante el fado, se refleja una la manera de sentir de un pueblo, transmitiendo el sentir y el alma de su día a día. Esta forma de vivir con las emociones del fado hace que la sociedad portuguesa viva y sienta en la música lo que ha sido parte de su historia combinando tanto épocas victoriosas como derrotas. De ahí que el fado tenga la capacidad de transmitir y activar la 


\section{GuSTAU OLCINA SEMPERE}

saudade, citada previamente, como una forma de mover los sentimientos y atender al aspecto de la nostalgia y la melancolía.

Por todo lo mencionado anteriormente, es necesario que la sociedad portuguesa valore y proteja el fado, ya que facilita la conexión con la vida diaria y hace que la música sea capaz de mover y calmar los sentimientos no solo de los portugueses sino también de todas la personas independientemente de su nacionalidad, ya que gran parte del misterio que tiene el fado es su capacidad de conmover el alma de todos los corazones, aunque no se entienda el significado de las palabras de sus canciones.

\section{BIBLIOGRAFIA}

Andrés, R. (1995). Diccionario de instrumentos musicales: Desde la antigüedad a J. S. Bach. Barcelona: Editorial Península.

Arraut, E. M. y Vielliard, J. M. (2004). The song of the Brazilian population of Humpback Whale Megaptera novaeangliae, in the year 2000: individual song variations and possible implications. Anais da Academia Brasileira de Ciências, 76 (2), pp. 373-380.

Bolaños, P. (2016). El estudio socio-histórico de las emociones y los sentimientos en las Ciencias Sociales del siglo XX. Revista de Estudios Sociales, 55, pp. 178-191.

Bodei, R. (2006). Destinos personales. Buenos Aires: El Cuenco de Plata.

Blood, A., Zatorre, R., Bermudez, P. y Evans, A. (1999). Emotional responses to pleasant and unpleasant music correlate with activity in paralimbic regions. Nature Neuroscience, 2 (4), pp. 382-387.

Brito, J. P. de (1999). “O fado: etnografia na cidade”. In: VELHO, G. (org.). Antropologia urbana: cultura e sociedade no Brasil e em Portugal. Rio de Janeiro: Zahar, pp. 24-42.

Carou, M. (2013). Tudo Isto É Fado. El Fado Lisboeta y Su Relación con la Lírica Galaicoportuguesa. Gramma, 23 (49), pp. 394-410.

Carvalho, P. (1903). História do Fado (com Ilustrações), ed. Facsimilada. Lisboa: Empresa da História de Portugal, Sociedade Editora.

Castañón, L. G. (2002). El fado vadío. Anaquel de estudios árabes, 13, p. 33.

Castelo-Branco, S. (2000). Voces de Portugal. Madrid: Akal.

Delgado, L. (2012). Psicanálise e Criatividade. Estudo psicodinâmico dos processos criativos artísticos. Lisboa: Edições Ispa. 


\section{EL FADO Y SU VINCULACIÓN CON EL TERRITORIO COMO ELEMENTO IDENTITARIO DE LA SOCIEDAD PORTUGUESA}

Fazio, D. (2016). “Corazón, canta y no llores, no llores que los dolores hay que espantarlos bailando". Revista de Estudios Sociales, enero-marzo, pp. 151-161.

Felisberto, F. J. D. (2013). Fado... um estado de alma. Doctoral Dissertation. Lisboa: ISPAInstituto Universitário

Fischerman, D. (2005). Escrito sobre música. Buenos Aires: Paidós.

Gomes, J. C. (2010). Matriz de identidade e mudança: o caso português. Revista de psicanálise, psicoterapia psicanalítica e desenvolvimento bumano, 1, pp. 49-66.

Halpern, M. (2004). O Futuro da Saudade: O novo fado e os novos fadistas. Lisboa: Dom Quixote.

Hinshelwood, R. D. (1992). Dicionário do pensamento Kleinianno. Porto Alegre: Artes Médicas.

Holton, K. D. (2006). Fado Historiograhy: Old Myths and New Frontiers. Portuguese Cultural Studies, 1, pp. 1-17.

Inácio, O., Santiago, F. y Cabral, P. C. (2004). The portuguese guitar acoustics: Part 1vibroacoustic measurements, en Proceedings of the IV Iberoamerican Acoustics Congress, Guimarães, Portugal. Disponible en: http://www.seaacustica.es/fileadmin/publicaciones/Guimaraes04_ID187.pdf

Levitin , D. (2000). In search of the musical mind. Cerebrum, 2 (4), pp. 1-24

Levitin, D. (2008). Tu cerebro y la música. Barcelona: RBA.

Levitin, D. J., Cole, K., Chiles, M., Lai, Z., Lincoln, A. y Bellugi, U. (2004). Characterizing the musical phenotype in individuals with Williams syndrome. Child Neuropsychology, 10 (4), pp. 223-247.

Lopes, S. (2011). Fado Portugal. 200 Anos de fado. Lisboa: Seven Muses Music Books.

Lourenço, E. (1988). Nós e a Europa ou as Duas Ražões (2 ${ }^{\mathrm{a}}$ Edição). Lisboa: Imprensa Nacional-Casa da Moeda.

Luiz. L. (2005). Vitrola Psicanalítica: canções que tocam na análise. São Paulo: Via Lettera.

Mazzarino, J. M., Morigi, V. J., Kaufmann, C., Farias, A. y Fernandes, D. A. (2011). Daily practices, consumption and citizenship. Anais da Academia Brasileira de Ciências, 83 (4), pp. 1481-1492.

Mendes, E. D. y Próchno, C. C. (2006). A ficção e a narrativa na literatura e na psicanálise. Revista de Psicanálise, Ano XIX, 185, pp. 43-51. 


\section{GuSTAU OLCINA SEMPERE}

Mortaigne, V. (2003). El Fado. Barcelona: Océano.

Nery, R. V. (2004). Para uma história do fado. Lisboa: Público: Corda Seca.

Nery, R. V. (2005). Para uma bistória do fado. Lisboa: Maia Douro.

Nery, R. V. (2010). Fado, en Enciclopédia da Música em Portugal no Século XX, pp. 433-453. Castelo Branco: Temas e Debates.

Nery, R. V. (2012). Fado: um património vivo. Lisboa: CT'T Correios de Portugal, SA.

Pereira, S. (2008). Circuito Museológico in Musen do Fado 1998-2008. Lisboa: EGEAC/Museu do Fado.

Pimentel, A. (1904). A Triste Canção do Sul: Subsídios para a história do fado, ed. Facsimilada. Lisboa: Livraria Central.

Ramírez, B. (2017). La identidad como construcción de sentido. Andamios, 14 (33), pp. 195-216.

Ribeiro, Á. (1937). Doutrina Fadista. (excerto da colectânea Portas do Conhecimento). Disponible en: http://www.ofilosofo.com/aribeiro-t5.htm.

Ribeiro, R. y Inácio, O. (2016). Experimental modal analysis of a fully assembled portuguese guitar. Actas del congreso EuroRegio 2016, Oporto, Portugal, pp. 1-10.

Romero, R. (2003). El fado lisboeta, sus orígenes y sus pasiones. Recuperado de: http://www.babab.com/no18/fado.php.

Sáez-González, J. M. (2007). Fados (Carlos Saura).Vivat Academia, 91, pp. 16-17.

Salimpoor, V. N.; Van den Bosch, I.; Kovacevic, N.; McIntosh, A. R.; Dagher, A.; Zatorre, R. J. (2013). Interactions between the nucleus accumbens and auditory cortices predict music reward value. Science, 340 (6129), pp. 216-219.

Sergl, M. J. (2007). O fado: características melódicas, rítmicas e de performance, en Anais do $3^{\circ}$ Congresso de Música e Mídia. Santos: Realejo Livros \& Edições. Disponible en: http://www.musimid.mus.br/3encontro/files/pdf/ Marcos\%20Julio\% 20Sergl.pdf.

Smith, A. D. (1997). Identidade Nacional. Lisboa: Gradiva.

Souroujon, G. (2011). Reflexiones en torno a la relación entre memoria, identidad e imaginación. Andamios, 8 (17), pp. 233-257. 
EL FADO Y SU VINCULACIÓN CON EL TERRITORIO COMO ELEMENTO IDENTITARIO DE LA SOCIEDAD PORTUGUESA

Valverde, P. (1999). O Fado é o coração: O corpo, as emoções e a performance no fado. Etnográfica, Vol. III (1), pp. 5-20.

Woody, R. H. y McPherson, G. E. (2010). Emotion and motivation in the lives of performers, en P. N. Juslin; J. A. Sloboda (eds.), Handbook of music and emotion: Theory, research, applications (pp. 401-424). Nueva York: Oxford University Press.

Fecha de recepción: 20/04/2018

Fecha de aceptación: 12/11/2018 